\title{
Factors Affecting Attitudes and Behavioral Intentions Toward In-app Mobile
}

\section{Advertisements}

Short title: Behavioral Intentions Toward Mobile Advertisements

\author{
Valdimar Sigurdsson, Reykjavik University \\ R. G. Vishnu Menon, Reykjavik University \\ Atli Geir Hallgrímsson, Reykjavik Univeristy
}

Nils Magne Larsen, UiT The Arctic University of Norway

Asle Fagerstrøm, Westerdals Oslo School of Arts, Communication and Technology,

The authors thank the Icelandic Research Fund (RANNIS) for partially funding this study. The authors also thank the GIKA anonymous reviewers for their careful reading and suggestions. Please send correspondence to Valdimar Sigurdsson, Reykjavik University, Menntavegur 1, Nautholsvik, 101 Reykjavik, Iceland (valdimars@ru.is); R. G. Vishnu Menon, School of Business, Reykjavik University, Menntavegur 1, Nautholsvik, 101 Reykjavik, Iceland (rgvishnu@ru.is); Atli Geir Hallgrímsson, School of Business, Reykjavik University, Menntavegur 1, Nautholsvik, 101 Reykjavik, Iceland (atli@zenter.is); Nils Magne Larsen, UiT The Arctic University of Norway, Campus Harstad, N-9480 Harstad, Norway (nils.magne.larsen@uit.no); Asle Fagerstrøm, Westerdals Oslo School of Arts, Communication and Technology, Schweigaardsgate 14, 0185 Oslo (fagas1@westerdals.no) 


\title{
BEHAVIORAL INTENTIONS TOWARD MOBILE ADVERTISEMENTS
}

\begin{abstract}
Mobile apps show a heavy usage pattern and compelling growth figures. This study seeks to examine consumers' attitudes toward in-mobile advertisements in terms of mobile advertising value. The samples are from the United Kingdom(UK) and India because the nationals of these countries exhibit a high degree of dissimilarity in a number of Hofstede's cultural dimensions. The findings suggest that factors such as perceived entertainment, credibility and information significantly improve attitudes toward in-app advertisements, and that the effectiveness of these advertisements is based on cultural differences. The participants from India exhibited more positive attitudes toward in-app advertisements than their counterparts from the UK. The entertainment factor had a greater impact on Indian, while credibility and information had a more significant impact on smartphone users from the UK.
\end{abstract}

Keywords: in-app mobile advertising, uses and gratification theory, Hofstede's model, attitudes, cross-culture marketing. 


\section{BEHAVIORAL INTENTIONS TOWARD MOBILE ADVERTISEMENTS}

\section{Introduction}

By the end of 2017, 2.4 billion people worldwide, or $54 \%$ of all mobile phone users, will be smartphone users (Murphy, 2017). Having a smart phone guarantees easy access to millions of mobile apps, and people everywhere seem to love such applications. As of March 2017, there were 2.2 million apps available on Apple's App Store alone, and 180 billion apps have been downloaded by consumers since the launch of the App Store in 2008 (Statista, 2017a,b). Just over the last year, the number of downloads has increased by as much as 70 percent (Apple.com, 2017). The many apps available on the store fall into six principal categories: informational, assistance, music, games, videos, and social media apps (Logan, 2017). While games (e.g., Candy Crush, Subway Surfers and Clash of Clans) have shown strong in-app purchase numbers, non-gaming apps now demonstrate the highest growth figures in terms of the frequency with which users open an app (Khalaf, 2016). It comes as no surprise that the most popular non-gaming apps include familiar social networking apps (such as Facebook, Twitter and Instagram), but users worldwide also exhibit an unbridled enthusiasm for apps providing assistance, such as those allowing users to check the weather, find restaurants, buy movie tickets, and keep track of their fitness (Logan, 2017). Apps have proved popular because, while most of them are free to download, they are easily accessible around the clock, and gratify a range of specific consumer needs. This popularity transforms into a usage pattern that brings apps to the forefront of consumers' media spending. As an example, the average US mobile user is projected to spend nearly two and a half hours per day on mobile apps by the end of 2017 (eMarketer, 2017). Because of their heavy usage pattern and strong growth figures, mobile apps represent enormous opportunities for developers as well as advertisers. Apple reports that its developers have earned more than $\$ 70$ billion since the launch of the App Store (Apple.com, 2017). The monetization model most frequently adopted by app developers is advertising, and in-app ads are projected to increase by 340 percent between 2015 and 2020 


\section{BEHAVIORAL INTENTIONS TOWARD MOBILE ADVERTISEMENTS}

(Statista, 2017c,d). The placement of ads in mobile apps is thus a fast-growing format and a key component of mobile advertising.

The advertising literature demonstrates that consumer attitudes toward advertising play a pivotal role in influencing exposure, attention and reaction toward an individual advertisement (Cheng, Blankson, Wang \& Chen, 2009). Thus, the effectiveness of in-app ads relies on consumers having favorable attitudes to such advertisements. A study by Raines (2013) indicates that young people in the UK tend to hold negative views toward in-app advertisements. They perceived in-app advertising as a highly vexatious form of communication that offers little entertainment value. In a similar, but qualitative, study conducted among young adults in India, respondents did not mind being exposed to in-app ads, provided the advertisements were relevant, personalized, useful, and not intrusive (Bhave, Jain, \& Roy, 2013). In the last few years, as smartphone technology has continued to progress, the app market has experienced exponential growth in terms of both the number of apps available and usage patterns, and in-app advertisers have had time to positively influence attitudes toward in-app advertisements. Thus, smartphone users' perceptions of in-app advertisements warrant further empirical examination. This gap in the literature is filled by a recent study by Logan (2017), which aims to examine attitudes toward in-app advertisements among young adults in the USA, as well as the present study, which compares the attitudes and behavioral intentions of smartphone users in the UK and India.

Attitudes have emerged as one of the most important factors affecting the success of advertising campaigns (Cheng et al., 2009). One drawback of previous research on mobile advertisements is the focus on older formats such as SMS and MMS advertisements (McCarthy \& Rowley, 2013). Another limitation of previous studies is their use of university and/or college students as samples (Choi, Hwang \& McMillan, 2008; Liu, Sinkovics, Pezderka, \& Haghirian, 2012). The third issue is related to standardization versus localization (see Khang, 


\section{BEHAVIORAL INTENTIONS TOWARD MOBILE ADVERTISEMENTS}

Han, Shin, Jung \& Kim, 2015). Research suggests that localized advertising is more effective than the use of a standardized approach worldwide (De Mooij \& Hofstede, 2010). This is mainly attributable to the cultural dissimilarities persisting between countries, which affect media and technology usage patterns (De Mooij \& Hofstede, 2010), and the ability to adapt an effective advertisement specifically developed for one country for use in another (Liu et al. 2012). Thus, understanding cultural differences is essential for developing effective crosscultural advertising campaigns. Although studies examining mobile advertising are growing in the literature, little is known about cultural differences in the context of in-app advertising (Billore \& Sadh, 2015). This paper examines the attitude of smartphone users toward in-app advertisements, the variables that influence such attitudes, and the effect of those attitudes on users' intentions to pay attention to, read, and click on advertisements. The paper utilizes samples from India and the UK to examine the effect of cultural differences on attitudes toward in-app advertisements. These two countries were selected as they show a high degree of dissimilarity in a number of cultural dimensions considered relevant to the explanation of variance in communication styles across cultures, and because neither one is among those most frequently examined in cross-cultural advertising research. Furthermore, results from previous studies taking samples from UK (Raines, 2013) and India (Bhave et al., 2013) show that both these countries are distinct when it comes to consumer attitudes toward in-app advertisements.

A conceptual model was developed to explicate the link between consumer beliefs, attitudes, intentions and behavior toward in-app advertisements. The belief factors utilized in the model were perceived entertainment, informativeness, credibility and irritation (Liu et al., 2012; Sundar \& Limperos, 2013; Tsang, Ho, \& Liang, 2004), and perceived personalization (Saadeghvaziri \& Hosseini, 2011; Xu, 2006). The objective was to examine the effects of these factors on the behavioral intentions of users to engage with in-app advertisements. The results show that favorable attitudes toward in-app advertisements have a positive impact on 


\section{BEHAVIORAL INTENTIONS TOWARD MOBILE ADVERTISEMENTS}

behavioral intention to click on, pay attention to, and read the advertisements. The results also suggest that mobile advertisers can use variables such as perceived entertainment to significantly improve these attitudes. Furthermore, culture differences have an impact on many of the examined relationships. There is a significant difference between the two countries in terms of user attitudes toward in-app advertisements: perceived entertainment had a greater impact on Indian smartphone users, while credibility had a greater impact on smartphone users from the UK. This study aims to provide valuable knowledge to scholars, as well as to businesses that are seeking to identify factors related to consumer attitudes, by showing that the cultural dimension should be taken into account while implementing local or international mobile advertising campaigns using in-app mobile advertisements.

\section{Conceptual model and hypothesis}

The uses and gratifications theory (UGT) research approach seeks to examine mobile use in light of socio-psychological needs, rather than focusing on the effects of the media itself on consumers. This paper investigates the factors affecting attitudes and behavioral intentions toward in-app mobile advertisements from a cross-cultural point of view. The paper builds on the main aspects of the theory of reasoned action (TRA), which argues that there is a direct relationship between attitudes, intentions and behavior (e.g., Fishbein \& Ajzen, 1975), as well as dimensions from Hofstede's $(1980,1984)$ cultural framework. Figure 1 sets out the conceptual model utilized in this study. Behavioral intention serves as a dependent variable and refers to the willingness to click on, pay attention to and read the advertisement. Attitude, defined as the overall attitude toward in-app advertisements, serves as an intervening variable, while entertainment, informativeness, credibility, irritation and personalization act as independent variables. Previous research suggests that these five constructs are the main determinants of attitudes toward mobile advertising (Tsang et al., 2004; Haron, Mun \& Ahmad, 


\section{BEHAVIORAL INTENTIONS TOWARD MOBILE ADVERTISEMENTS}

2015; Liu et al., 2012; Xu, 2006). The impact of cultural differences on each of the belief factors, and on behavioral intention, is also examined. Twelve hypotheses are derived in line with the model. Hypothesis 1 is based on TRA, hypotheses 2 to 6 on the UGT and the remainder (7 to 12) on selected dimensions from Hofstede's cultural framework $(1980,1984)$.

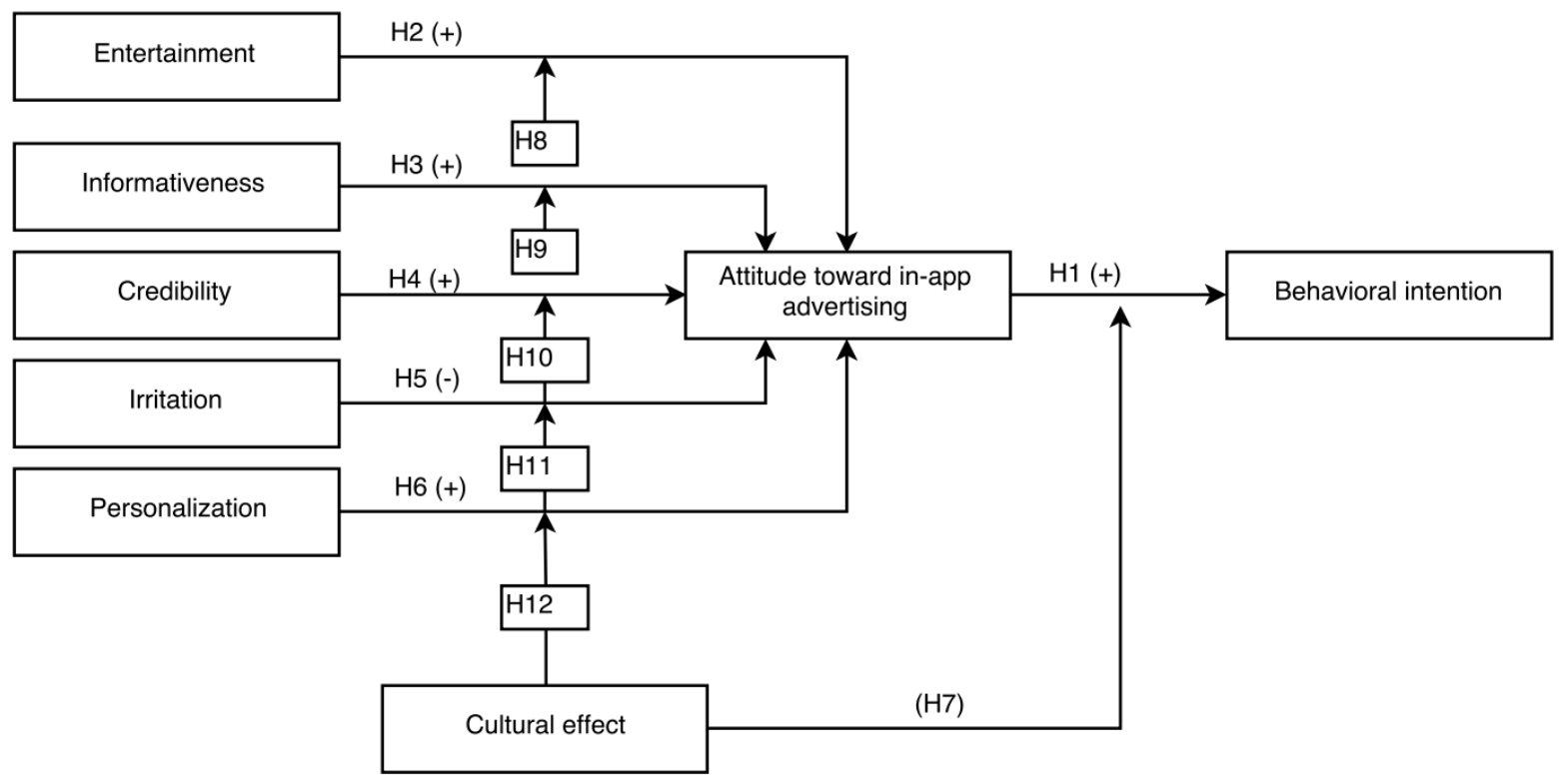

Figure 1. The conceptual model

\subsection{The relationship between attitudes and behavioral intention}

The attitude-intention relationship in TRA has been confirmed in multiple studies in which participants have exhibited favorable behavioral intentions toward advertising alongside positive attitudes toward advertising (Izquierdo-Yusta, Olarte-Pascual, \& Reinares-Lara, 2015; Wang \& Sun, 2010). This provides the basis for the following hypothesis:

H1: A favorable attitude toward in-app advertising will have a positive effect on the behavioral intention to click on, pay attention to, and read in-app advertisements.

\subsection{Entertainment}

In the context of UGT, McQuail (1983) defines entertainment as the ability to fulfill an 


\section{BEHAVIORAL INTENTIONS TOWARD MOBILE ADVERTISEMENTS}

audience's needs for escapism, diversion, or aesthetic or emotional enjoyment. There is a strong relationship between perceived entertainment and advertising value in both traditional advertisements and mobile advertisements (Hagharian \& Madleberger, 2005; Haron et al., 2015; Tsang et al., 2004). Extant research also shows that perceived entertainment has a greater effect on advertisement value than other factors such as informativeness, irritation and credibility (Ducoffe 1995, 1996; Haghirian, Madleberger, \& Tanuskova, 2005). Despite these findings, the literature contains a number of inconsistencies. According to Peng and Spencer (2006), mobile phones are sensitive private devices. When they are used for advertising, consumers might be less concerned with the entertainment value of an advertisement than with its informative content. This claim receives some support from a study by Jun and Lee (2007), which suggests that entertainment does not have a significant impact on attitude. However, the researchers do intimate that the results could be explained by cultural differences. On consideration of the overall findings, the second hypothesis is:

H2: Perceived entertainment will have a positive influence on attitudes toward in-app advertising.

\subsection{Informativeness}

From the perspective of UGT, informativeness refers to the extent to which the advertisement provides the consumer with useful information. It increases consumers' knowledge and understanding and satisfies their cognitive need for information about the advertised product or service (Ducoffe 1995; Katz, Haas \& Gurevitch, 1973). The quality of information on a company's website and in mobile advertisements has been shown to have a considerable impact on customers' estimation of that company, and consequently could have a marked influence on customers' inclination to trust the company and its products (Fung \& Lee, 1999; Kaasinen, 2003; Siau \& Shen 2003). Advertisements that provide pertinent information are less likely to 


\section{BEHAVIORAL INTENTIONS TOWARD MOBILE ADVERTISEMENTS}

be perceived as annoying (Chowdhury, Parvin, Weitenberner \& Becker, 2006), and have greater value than traditional media (Ducoffe, 1995), and online (Ducoffe, 1996) and SMS advertisements (e.g., Zabadi, Shura, \& Elsayed 2012). Furthermore, studies have also shown that informativeness is positively associated with consumer attitudes toward SMS advertising (Zabadi et al., 2012; Tsang et al., 2004; Haghirian et al., 2005). Based on these findings, the third hypothesis is:

H3: Perceived informativeness will have a positive influence on attitudes toward in-app advertising.

\subsection{Credibility}

Credibility has been considered a key attribute in advertising as consumers are likely to avoid or ignore advertisements that lack credibility (Moore \& Rogers, 2005). MacKenzie and Lutz (1989) describe advertising credibility as "the extent to which the consumer perceives claims made about the brand in the ad to be truthful and believable" (p. 51). Credibility has been shown to vary between different advertising media. Moore and Rodgers (2005) report that participants consider advertisements in newspapers to have the greatest degree of credibility, while internet advertisements are thought to be the least credible, unless the message originates from a strong brand. However, in a more recent study, Nielsen (2015) finds that online channels are the second most trusted advertising format after recommendations from friends, with mobile advertisements being considered the least credible. A high degree of perceived credibility is positively associated with advertising value (Bracket \& Carr, 2001; Hagharian \& Madleberger, 2005; Liu et al., 2012), and is directly related to attitudes toward traditional, online and mobile advertisements (Xu, 2006; Tsang et al., 2004). Based on these findings, the fourth hypothesis is:

H4: Perceived credibility will have positive influence on attitudes toward in-app advertising. 


\section{BEHAVIORAL INTENTIONS TOWARD MOBILE ADVERTISEMENTS}

\subsection{Irritation}

In the context of advertising, irritation refers to the state of being annoyed, impatient and even moderately angry (Ducoffe, 1996). Irritation can take the form of feeling that your intelligence has been insulted, experiencing annoying messages, or being subjected to other stimuli (Bracket \& Carr, 2001). The superabundance of information sent by marketers through mobile channels can distract and confuse recipients, and the information itself can be perceived as offensive, insulting, manipulative or annoying. This in turn can lead to irritation and should, according to UGT, reduce advertising effectiveness (Ducoffe, 1996; Xu, 2006). Irritation is linked to negative effects on attitudes toward advertisements and their perceived value (Ducoffe, 1996; Tsang et al., 2004). Therefore:

H5: Perceived irritation will have a negative influence on attitudes toward in-app advertising.

\subsection{Personalization}

Personalized mobile advertising refers to the act of sending advertising messages to mobile devices based on demographic (e.g. income), user preference (e.g. preferred products), context (e.g. location and user activities) and content (e.g. brand name) factors (Xu, 2006). An advertisement is said to be personalized when it is customized to fit an individual's preferences (Bauer, Reichardt, Barnes, \& Neumann, 2005). Personalization is one of the most important factors affecting consumers' attitudes toward advertisements, and an effective way to prevent mobile advertising from being perceived as intrusive (Xu, 2006). Personalized advertisements can also act as an effective way to reduce irritation and enhance the perceived entertainment value of advertisements (Kim \& Han, 2014). Some claim that the success of mobile advertising campaigns depends on whether the advertiser manages to create and send relevant and personalized content to mobile users $(\mathrm{Xu}, 2006)$. On the basis of these findings, the sixth hypothesis is: 


\section{BEHAVIORAL INTENTIONS TOWARD MOBILE ADVERTISEMENTS}

H6: Perceived personalization will have a positive influence on attitudes toward in-app advertising.

\subsection{Cultural influence - A cross-cultural comparison}

According to Hofstede (1980, p.24) culture is "the collective programming of the human mind that distinguishes the members of one human group from those of another." Culture, in this sense, consists of the shared values (or common characteristics) in a society or a country that influence how the members of that society or country respond to their environment (Hofstede, 1980). Various models for describing and understanding culture have emerged in recent decades. They include among others, the work of Hofstede (1984, 2001), Schwartz (1994); and Schwartz and Bilsky (1987), and the GLOBE study (House, Hanges, Javidan, Dorfman, \& Gupta, 2004). The Hofstede model is frequently used in global marketing and advertising research to explain differences in branding strategy and communication (De Mooij \& Hofstede, 2010; Okazaki \& Mueller, 2007). In contrast, Schwartz's cultural values model has not enjoyed widespread implementation in cross-culture advertising research (Terlutter, Diehl, \& Mueller, 2006), and the most recent framework, the GLOBE study, has received only limited attention (Okazaki \& Mueller, 2007). Thus, Hofstede's model appears to be the framework most frequently utilized in cross-cultural advertising research and the most widely accepted of all available cultural frameworks. Since the literature also includes research on manifestations of the Hofstede cultural dimensions which hold the greatest relevance for advertising (see De Mooij \& Hofstede, 2010), this paper found Hofstede's work to be a suitable framework within which to examine cultural differences.

According to De Mooij and Hofstede (2010), the dimensions of most relevance for explaining variations in communication styles across cultures are power distance, individualism/collectivism and uncertainty avoidance. De Mooij and Hofstede (2010, p.88-89) 


\section{BEHAVIORAL INTENTIONS TOWARD MOBILE ADVERTISEMENTS}

define power distance as "the extent to which less powerful members of a society accept and expect that power is distributed unequally," uncertainty avoidance as "intolerance for uncertainty and ambiguity," and individualism versus collectivism as "people looking after themselves and their immediate family only, versus people belonging to in-groups that look after them in exchange for loyalty."

There are important differences between the UK and India along these cultural dimensions. India is a high-power-distance society, with both collectivist and individualist traits, while the UK is a highly individualistic society with a low power distance (Hofstede, 2001). Although the two countries share the cultural characteristic of low uncertainty avoidance (Hofstede, 2001), India scores somewhat higher on this dimension than the UK. As a result of its more individualistic culture, the communication style in the UK is, compared to India, much more low-context (De Mooij \& Hofstede, 2010). The distinction between high-context and low-context cultures originates from Hall (1976), and is of critical importance in understanding how advertising works across cultures. Hall's (1976) cultural framework is based on qualitative insights rather than quantitative data, and does not rank different countries. Nevertheless, Hall (1976) identifies Western and Northern European countries such as the UK as low-context cultures, whereas countries in the Eastern Mediterranean, Latin America, and Asia, such as India, are classified as high-context cultures. Low-context communication is characterized by explicit verbal statements, while high-context communication is less direct (De Mooij \& Hofstede, 2010). The role of advertising therefore differs between low-context cultures, where advertisements aim at persuasion, and high-context cultures, where they must aim at creating trust.

Research conducted on various aspects of advertisements has shown that there can be a significant difference across cultures, particularly between Western and Eastern cultures (Choi et al., 2008; Hong, Muderrisoglu, \& Zinkhan, 1987). Cross-cultural validity testing by 


\section{BEHAVIORAL INTENTIONS TOWARD MOBILE ADVERTISEMENTS}

Lee and Green (1991) demonstrates the applicability of the theory of reasoned action to both individualist/low-power-distance cultures and collectivist/high-power-distance cultures, and points to differences in the relative importance of personal attitudes and societal norms in determining behavioral intentions. People in high-power-distance cultures tend not to question authority, but rather accept the hierarchical order without any need for justification (De Mooij \& Hofstede, 2010). Individuals from high-power-distance cultures may therefore be more responsive to advertising than individuals from low-power-distance cultures, who are more skeptical, less likely to bow to authority, and therefore likelier to entertain doubts regarding claims made in advertising (Wang \& Sun, 2010). Therefore:

H7: The effect of attitude on behavioral intention to click on, pay attention to, and read advertisements is greater for Indian smartphone users than for those from the UK.

The way people acquire information to prepare themselves for purchases also varies in accordance with power distance. According to De Mooij and Hofstede (2010, p. 96) people in collectivist and/or high-power-distance cultures "acquire information more via implicit, interpersonal communication and base their buying decisions more on feelings and trust in the company." In contrast, people in individualistic cultures with low power distance have a proclivity for acquiring explicit information through media and friends (De Mooij \& Hofstede, 2010), and base their decisions on "facts." These cultural traits have been confirmed by several cross-cultural advertising studies (e.g. Taylor, Miracle, \& Wilson, 1997; Hong, et al., 1987). This premise is also corroborated by Choi et al. (2008) study, which demonstrates that informativeness is of greater importance to American consumers than it is to Korean consumers in shaping attitudes toward mobile advertisements. Therefore:

H8: The effect of entertainment on attitudes toward in-app advertising is greater for Indian smartphone users than for those from the UK. 


\section{BEHAVIORAL INTENTIONS TOWARD MOBILE ADVERTISEMENTS}

H9: The effect of informativeness on attitudes toward in-app advertising is greater for smartphone users from the UK than for Indian smartphone users.

Consumers from high-uncertainty-avoidance cultures require greater levels of reassurance and uncertainty reduction, and thus are likelier to prefer credible brands (Dawar \& Parker, 1994). A cross-cultural study by Erdem, Swait, and Valenzuela (2006) further confirms that brand credibility affects consumer choice under uncertainty across cultures, and that uncertainty avoidance and collectivism increase the overall impact of credibility. Similarly, Liu et al. (2012) find the effect of advertisement credibility on the value of SMS advertising to be greater for mobile users in Austria (an individualistic culture) than it is for mobile users in Japan (a collectivistic culture). As previously noted, India has a slightly higher uncertainty-avoidance score (Hofstede, 2001) than the UK. However, a study by Singh, Zhao, and Hu (2005) reveals that Indian websites have high levels of uncertainty-avoidance features - even higher than China and Japan. This indicates that individuals from India might have an even more pronounced tendency to avoid uncertainty than the Hofstede model suggests. Thus, we hypothesize:

H10: The effect of credibility on attitudes toward in-app advertising is greater for Indian smartphone users than for those from the UK.

Research has demonstrated that people from high-uncertainty-avoidance (UA) cultures are less receptive of novelty, such as new technology and innovations (De Mooij \& Hofstede, 2010; Tellis, Stremersch, \& Yin, 2003), and that high power distance (PD) also has an adverse effect on the adoption of new technology (Van Everdingen \& Waarts, 2003). Furthermore, the study by Liu et al. (2012) shows annoyance to have a significantly greater effect on the value of SMS advertising for Japanese mobile users (who have a high PD and high UA) than for Austrian users (who have a low PD and low UA). This result suggests that consumers in cultures 


\section{BEHAVIORAL INTENTIONS TOWARD MOBILE ADVERTISEMENTS}

characterized by high power distance and high uncertainty avoidance are more sensitive to advertisements on new technological platforms. We therefore hypothesize:

H11: The effect of irritation on attitudes toward in-app advertisements is greater for Indian smartphone users than for those from the UK.

The individualism dimension has also been shown to affect the personalization of communication messages. According to De Mooij (2004), advertisements in individualistic cultures are more direct, explicit and personal, and consumers prefer a more personalized "lecture" style in advertising. Pronouns such as "you" and "we" are more commonly used, while collectivist cultures prefer a less direct style of communication (De Mooij, 2004). Company websites in America (a highly individualistic culture), for example, demonstrate significantly more personalization compared to those in China (a collectivist culture) (Singh et al. 2005). Furthermore, results show that, while personalization improves the efficacy of advertising in highly individualistic cultures such as the UK, it generates adverse effects in collectivist cultures. Additionally, the results of research conducted by Moon, Chadee, and Tikoo (2008) show that people from highly individualistic cultures are more likely to buy personalized products. Based on these findings, the following hypothesis is proposed:

H12: The effect of personalization on attitudes toward in-app advertisements is greater for smartphone users from the UK than for Indian smartphone users.

\section{Method}

\subsection{Participants, setting, and product}

The study was conducted using a crowd-sourcing platform that allows individuals and businesses to outsource a variety of small tasks that computers are incapable of doing. The study participants were restricted to those from India and the UK, and were limited to one IP 


\section{BEHAVIORAL INTENTIONS TOWARD MOBILE ADVERTISEMENTS}

address to make sure that no participant completed the survey more than once. A total of 300 respondents participated, of which 49 were excluded as they failed to meet the requirements. The remaining 251 participants comprised 169 males and 82 females, with nine participants aged under 21, 68 aged between 22 and 34, 16 falling into the 35 to 44-year-old category, 5 between the ages of 45 and 54, 2 aged 55 to 64, and none older than 64.

\subsection{Design and procedure}

The data were gathered by means of a survey. The relationship between the variables was analyzed using partial least squares structural equation modelling. The survey was pre-tested using a random selection of 20 participants. The pre-test revealed that two participants exhibited acquiescence bias by answering "Strongly agree" to all of the questions. As a result, attentional filters were added to the questionnaire and those who failed to answer the questions correctly were excluded from the study.

\subsection{Measurement}

Based on the existing literature in relation to various types of advertisements, five constructs were identified as the most relevant in the context of this study. The questionnaire consisted of 32 questions. Four of these questions were used to assess information about age, education, gender and nationality. The remainder of the items were based on previous studies conducted on various advertising formats. The items were in the form of statements and were answered using a five-point Likert scale ranging from "Strongly disagree" to "Strongly agree." Table 2 sets out the measurement items for each construct. 


\section{BEHAVIORAL INTENTIONS TOWARD MOBILE ADVERTISEMENTS}

Table 2. Constructs, indicators, questions and references.

\begin{tabular}{|c|c|c|c|}
\hline Constructs & Indicators & Questions & References \\
\hline \multirow[t]{2}{*}{ Attitude } & ATT1 & $\begin{array}{l}\text { I'm favorably disposed toward in-app } \\
\text { mobile advertising }\end{array}$ & $\begin{array}{l}\text { Yang, Kim, \& Yoo } \\
(2013)\end{array}$ \\
\hline & ATT2 & $\begin{array}{l}\text { Overall, in-app mobile advertising is } \\
\text { positive }\end{array}$ & Yang et al. (2013) \\
\hline \multirow[t]{4}{*}{ Behavioral Intention } & BI1 & $\begin{array}{l}\text { I'm willing to pay attention to and read } \\
\text { in-app mobile advertisements }\end{array}$ & Self-created \\
\hline & $\mathrm{BI} 2$ & $\begin{array}{l}\text { I'm willing to click on in-app mobile } \\
\text { advertisements }\end{array}$ & Self-created \\
\hline & $\mathrm{BI} 3$ & $\begin{array}{l}\text { I think it's likely that I will pay attention } \\
\text { to and read in-app mobile } \\
\text { advertisements in the future }\end{array}$ & Self-created \\
\hline & BI4 & $\begin{array}{l}\text { I think it's likely that I will click on in- } \\
\text { app mobile advertisements in the future }\end{array}$ & Self-created \\
\hline \multirow[t]{3}{*}{ Credibility } & CRE1 & $\begin{array}{l}\text { I believe that in-app mobile advertising } \\
\text { is credible }\end{array}$ & $\begin{array}{l}\text { Chowdhury et al. } \\
(2006)\end{array}$ \\
\hline & CRE2 & $\begin{array}{l}\text { I feel that in-app mobile advertising } \\
\text { poses no risks }\end{array}$ & $\begin{array}{l}\text { Chowdhury et al. } \\
\text { (2006) }\end{array}$ \\
\hline & CRE3 & I trust in-app mobile advertisements & $\begin{array}{l}\text { Chowdhury et al. } \\
\text { (2006) }\end{array}$ \\
\hline \multirow[t]{3}{*}{ Entertainment } & ENT1 & $\begin{array}{l}\text { In-app mobile advertisements are } \\
\text { enjoyable }\end{array}$ & Wang \& Sun (2010) \\
\hline & ENT2 & $\begin{array}{l}\text { In-app mobile advertisements are } \\
\text { pleasant }\end{array}$ & Wang \& Sun (2010) \\
\hline & ENT3 & $\begin{array}{l}\text { In-app mobile advertisements are } \\
\text { entertaining }\end{array}$ & Wang \& Sun (2010) \\
\hline \multirow[t]{3}{*}{ Informativeness } & INF1 & $\begin{array}{l}\text { In-app mobile advertisements provide } \\
\text { the information I need }\end{array}$ & Tsang et al. (2004) \\
\hline & INF2 & $\begin{array}{l}\text { In-app mobile advertisements are a good } \\
\text { source of product/service information }\end{array}$ & Wang \& Sun (2010) \\
\hline & INF3 & $\begin{array}{l}\text { In-app mobile advertisements supply } \\
\text { relevant information }\end{array}$ & Wang \& Sun (2010) \\
\hline \multirow[t]{3}{*}{ Irritation } & IRR1 & $\begin{array}{l}\text { The contents of in-app mobile } \\
\text { advertisements are often annoying }\end{array}$ & $\mathrm{Xu}(2006)$ \\
\hline & IRR2 & $\begin{array}{l}\text { I feel that in-app mobile advertisements } \\
\text { are irritating }\end{array}$ & Xu (2006) \\
\hline & IRR3 & $\begin{array}{l}\text { In-app mobile advertisements disturb my } \\
\text { use of mobile devices. }\end{array}$ & $\mathrm{Xu}(2006)$ \\
\hline \multirow[t]{3}{*}{ Personalization } & PER1 & $\begin{array}{l}\text { In-app mobile advertisements display } \\
\text { personalized messages }\end{array}$ & Gao \& Zang (2014) \\
\hline & PER2 & $\begin{array}{l}\text { I feel that the in-app mobile } \\
\text { advertisements I receive are relevant to } \\
\text { my job and activities }\end{array}$ & Gao \& Zang (2014) \\
\hline & PER3 & $\begin{array}{l}\text { In-app mobile advertisements are } \\
\text { customized to my needs }\end{array}$ & Gao \& Zang (2014) \\
\hline
\end{tabular}

\subsection{Evaluation of the structural model}




\section{BEHAVIORAL INTENTIONS TOWARD MOBILE ADVERTISEMENTS}

The internal consistency of the constructs was evaluated using Cronbach's alpha. All constructs except the irritation construct in the UK group achieved the minimum level of 0.70 . The average variance extracted (AVE) was measured and exceeded the threshold of 0.5 for all of the constructs. The composite factor reliability (CFR) values were also measured. Due to acceptable AVE and CFR values, the irritation construct in the UK group was retained despite failing to reach minimum alpha levels. Table 3 sets out the reliability and validity data for each construct.

Table 3. Reliability and validity

\begin{tabular}{|c|c|c|c|c|c|c|c|c|c|}
\hline & & India & & & UK & & & Combined & \\
\hline Constructs & $\begin{array}{c}\text { Cronbach's } \\
\text { Alpha }\end{array}$ & $\begin{array}{l}\text { Composite } \\
\text { Reliability }\end{array}$ & $\begin{array}{l}\text { Average } \\
\text { Variance } \\
\text { Extracted }\end{array}$ & $\begin{array}{c}\text { Cronbach's } \\
\text { Alpha }\end{array}$ & $\begin{array}{l}\text { Composite } \\
\text { Reliability }\end{array}$ & $\begin{array}{c}\text { Average } \\
\text { Variance } \\
\text { Extracted }\end{array}$ & $\begin{array}{c}\text { Cronbach's } \\
\text { Alpha }\end{array}$ & $\begin{array}{l}\text { Composite } \\
\text { Reliability }\end{array}$ & $\begin{array}{l}\text { Average } \\
\text { Variance } \\
\text { Extracted }\end{array}$ \\
\hline Attitude & 0.90 & 0.95 & 0.91 & 0.91 & 0.95 & 0.91 & 0.90 & 0.95 & 0.91 \\
\hline Behavioral intention & 0.93 & 0.95 & 0.83 & 0.95 & 0.96 & 0.87 & 0.94 & 0.96 & 0.85 \\
\hline Credibility & 0.79 & 0.88 & 0.70 & 0.86 & 0.91 & 0.78 & 0.83 & 0.90 & 0.74 \\
\hline Entertainment & 0.91 & 0.95 & 0.85 & 0.94 & 0.96 & 0.90 & 0.93 & 0.95 & 0.88 \\
\hline Informativeness & 0.89 & 0.93 & 0.82 & 0.93 & 0.95 & 0.87 & 0.91 & 0.95 & 0.85 \\
\hline Irritation & 0.78 & 0.87 & 0.70 & 0.68 & 0.82 & 0.61 & 0.72 & 0.84 & 0.64 \\
\hline Personalization & 0.71 & 0.83 & 0.63 & 0.86 & 0.92 & 0.78 & 0.80 & 0.88 & 0.71 \\
\hline
\end{tabular}

The discriminant validity was assessed to determine the extent to which the latent variables are distinct. Table 4 sets out the average variance extracted (AVE) for each of the constructs and its correlations. From Table 4, we see that the square root of the AVE for each construct is greater than the correlation involving the constructs, which corroborates their validity as discriminants (Chin, 2010).

Table 4. Correlations and AVE for each country

\begin{tabular}{|c|c|c|c|c|c|c|c|}
\hline \multicolumn{8}{|l|}{ India } \\
\hline & Attitude & $\begin{array}{l}\text { Behavioral } \\
\text { intention }\end{array}$ & Credibility & Entertainment & Information & Irritation & $\begin{array}{l}\text { Personali } \\
\text {-zation }\end{array}$ \\
\hline Attitude & 0.95 & & & & & & \\
\hline Behavioral intention & 0.91 & 0.91 & & & & & \\
\hline Credibility & 0.75 & 0.71 & 0.84 & & & & \\
\hline
\end{tabular}




\section{BEHAVIORAL INTENTIONS TOWARD MOBILE ADVERTISEMENTS}

\begin{tabular}{|c|c|c|c|c|c|c|c|}
\hline Entertainment & 0.92 & 0.87 & 0.76 & 0.92 & & & \\
\hline Informativeness & 0.79 & 0.74 & 0.72 & 0.78 & 0.9 & & \\
\hline Irritation & -0.61 & -0.58 & -0.5 & -0.63 & -0.53 & 0.84 & \\
\hline Personalization & 0.73 & 0.71 & 0.6 & 0.72 & 0.8 & -0.41 & 0.79 \\
\hline \multicolumn{8}{|l|}{ UK } \\
\hline & Attitude & $\begin{array}{l}\text { Behavioral } \\
\text { intention }\end{array}$ & Credibility & Entertainment & Information & Irritation & $\begin{array}{l}\text { Personali } \\
\text {-zation }\end{array}$ \\
\hline Attitude & 0.96 & & & & & & \\
\hline Behavioral intention & 0.89 & 0.93 & & & & & \\
\hline Credibility & 0.82 & 0.77 & 0.88 & & & & \\
\hline Entertainment & 0.9 & 0.88 & 0.78 & 0.95 & & & \\
\hline Informativeness & 0.85 & 0.87 & 0.81 & 0.87 & 0.93 & & \\
\hline Irritation & -0.7 & -0.64 & -0.63 & -0.7 & -0.62 & 0.78 & \\
\hline Personalization & 0.69 & 0.69 & 0.68 & 0.74 & 0.79 & -0.39 & 0.89 \\
\hline \multicolumn{8}{|l|}{ Combined } \\
\hline Construct & Attitude & $\begin{array}{l}\text { Behavioral } \\
\text { intention }\end{array}$ & Credibility & Entertainment & Information & Irritation & $\begin{array}{l}\text { Personali } \\
\text {-zation }\end{array}$ \\
\hline Attitude & 0.96 & & & & & & \\
\hline Behavioral intention & 0.9 & 0.92 & & & & & \\
\hline Credibility & 0.79 & 0.75 & 0.86 & & & & \\
\hline Entertainment & 0.91 & 0.88 & 0.77 & 0.94 & & & \\
\hline Informativeness & 0.83 & 0.81 & 0.77 & 0.83 & 0.92 & & \\
\hline Irritation & -0.66 & -0.61 & -0.57 & -0.66 & -0.57 & 0.8 & \\
\hline Personalization & 0.71 & 0.71 & 0.65 & 0.74 & 0.81 & -0.4 & 0.84 \\
\hline
\end{tabular}

To ensure convergent validity, confirmatory factor analysis (CFA) was conducted. As set out in Table 5, all of the outer loadings are greater than 0.5 , with the majority exhibiting strong loadings in excess of 0.7 . All of the constructs are significant at $p<0.1$. 


\section{BEHAVIORAL INTENTIONS TOWARD MOBILE ADVERTISEMENTS}

Table 5. Factor loadings of scale items

\begin{tabular}{|c|c|c|c|c|}
\hline & & India & UK & $\begin{array}{c}\text { Both } \\
\text { countries } \\
\end{array}$ \\
\hline Constructs & Indicator & Loadings & Loadings & Loadings \\
\hline \multirow{2}{*}{ Attitude } & ATT1 & 0.95 & 0.96 & 0.96 \\
\hline & ATT2 & 0.95 & 0.96 & 0.95 \\
\hline \multirow{4}{*}{ Behavioral intention } & BHI1 & 0.92 & 0.92 & 0.92 \\
\hline & BHI2 & 0.88 & 0.93 & 0.90 \\
\hline & BHI3 & 0.92 & 0.94 & 0.93 \\
\hline & BHI4 & 0.92 & 0.94 & 0.93 \\
\hline \multirow{3}{*}{ Credibility } & CRED1 & 0.85 & 0.88 & 0.86 \\
\hline & CRED2 & 0.77 & 0.84 & 0.82 \\
\hline & CRED3 & 0.89 & 0.92 & 0.91 \\
\hline \multirow{3}{*}{ Entertainment } & ENT1 & 0.93 & 0.96 & 0.95 \\
\hline & ENT2 & 0.94 & 0.95 & 0.94 \\
\hline & ENT3 & 0.90 & 0.93 & 0.92 \\
\hline \multirow{3}{*}{ Informativeness } & INF1 & 0.90 & 0.94 & 0.92 \\
\hline & INF2 & 0.89 & 0.94 & 0.92 \\
\hline & INF3 & 0.92 & 0.92 & 0.93 \\
\hline \multirow{3}{*}{ Irritation } & IRR1 & 0.83 & 0.84 & 0.84 \\
\hline & IRR2 & 0.87 & 0.83 & 0.86 \\
\hline & IRR3 & 0.81 & 0.66 & 0.70 \\
\hline \multirow{3}{*}{ Personalization } & PER1 & 0.57 & 0.82 & 0.72 \\
\hline & PER2 & 0.90 & 0.89 & 0.89 \\
\hline & PER3 & 0.87 & 0.94 & 0.90 \\
\hline
\end{tabular}

\section{Results}

\subsection{Structural model}

Partial least square path analysis was used to examine the relationship between the constructs and to scrutinize the hypotheses. As shown in Figure 2, attitudes explain $81 \%$ of the variance in the behavioral intention to read, pay attention to and click on mobile advertisements, while the independent variables explain $86 \%$ of the variance in attitudes toward advertisements. 


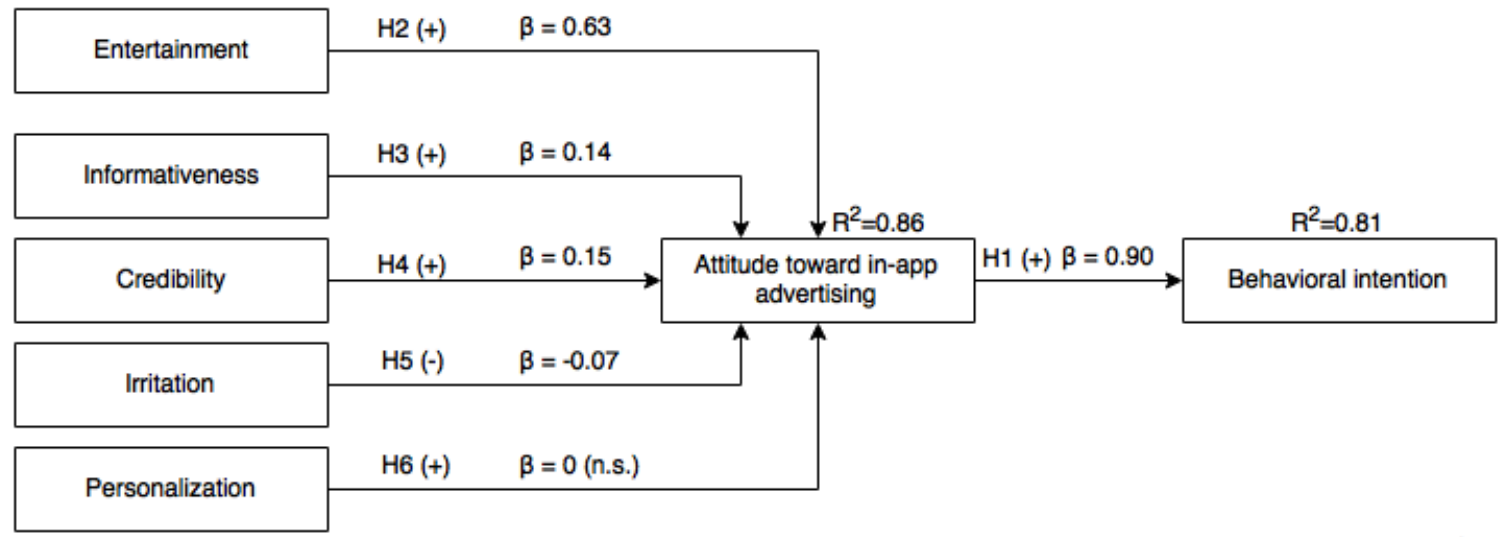

Note: n.s. = not significant

Figure 2. Structural model with results.

Table 6 shows the path coefficients for the whole sample. The results illustrate the impact of attitude on behavioral intention $(\beta=0.90, \mathrm{p}<0.01)$ and confirm $H 1$. Regarding the factors influencing attitude, entertainment had the greatest impact on attitude, demonstrating a strong effect $(\beta=0.63, \mathrm{p}<0.01)$ and confirming $H 2$. Informativeness also exhibited a significant impact on attitude $(\beta=0.14, \mathrm{p}<0.01)$, though slightly less than credibility, confirming $H 3$. Credibility had the second greatest impact on attitude $(\beta=0.15, \mathrm{p}<0.01)$, confirming H4. H5 was also supported, as irritation exhibited a marginal negative effect on attitude toward in-app advertisements $(\beta=-0.07, \mathrm{p}<0.05)$. Personalization of in-app advertisements had no significant effect on attitude.

Table 6. Path coefficients for the whole sample

\begin{tabular}{lccc}
\hline \multicolumn{1}{c}{ Relationship } & $\begin{array}{c}\text { Path } \\
\text { coefficient }\end{array}$ & T-Statistics & P-Values \\
\hline Attitude -> Behavioral intention & 0.90 & 65.82 & 0 \\
Entertainment -> Attitude & 0.63 & 9.1 & 0 \\
Informativeness -> Attitude & 0.14 & 2.65 & 0.01 \\
Credibility -> Attitude & 0.15 & 2.68 & 0.01 \\
Irritation -> Attitude & -0.07 & 2.2 & 0.03 \\
Personalization -> Attitude & 0 & 0.09 & 0.93 \\
\hline
\end{tabular}

\subsection{Cross-cultural comparison}




\section{BEHAVIORAL INTENTIONS TOWARD MOBILE ADVERTISEMENTS}

To assess the validity of the remaining hypotheses and to examine the differences between the two countries, a comparison of the UK and India was undertaken. As shown in Figure 3, there are notable differences between the two countries.

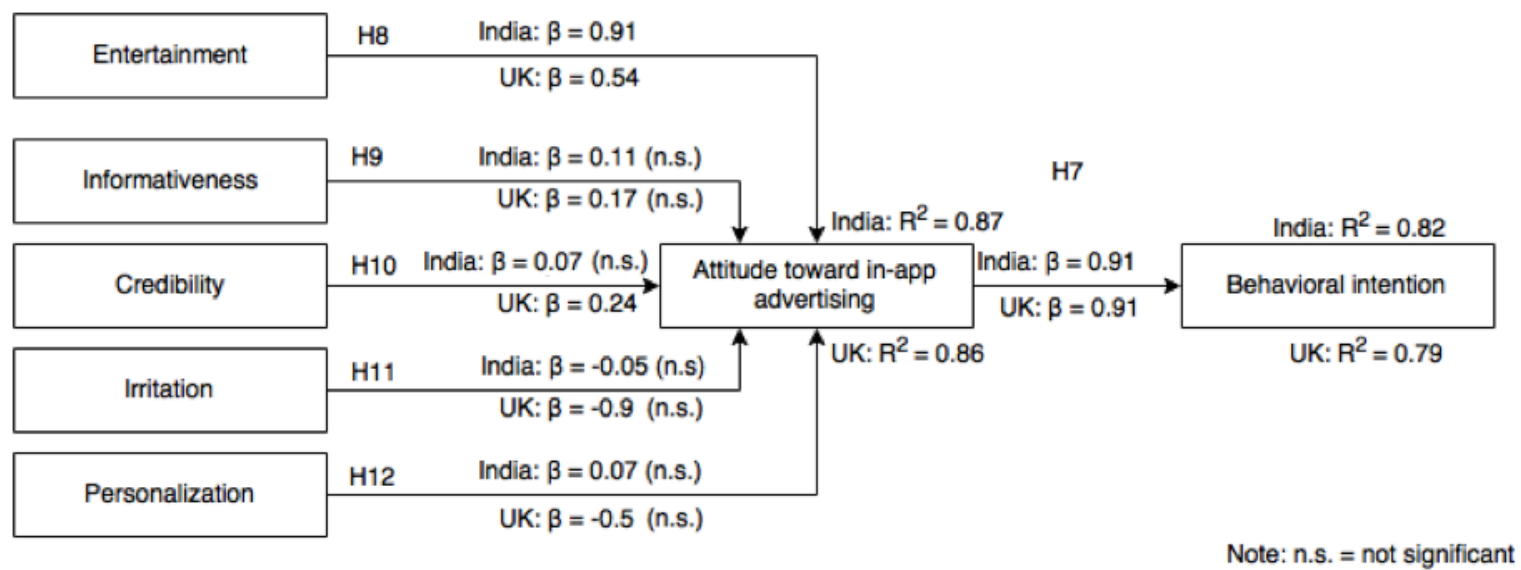

Figure 3. Structural model comparing India and the UK

Table 7 shows the path coefficients for India and the UK. Attitude has a more significant impact on behavioral intention in India $(\beta=0.91, \mathrm{p}<0.01)$ than in the $\mathrm{UK}(\beta=0.89, \mathrm{p}<0.01)$, confirming H7. Entertainment also has a greater impact on attitude toward in-app mobile advertisements in India $(\beta=0.70 p<0.01)$ compared to the $\operatorname{UK}(\beta=0.54, p<0.01)$, confirming H8. Furthermore, while credibility has a moderate effect on attitude in the UK $(\beta=0.24, \mathrm{p}<$ 0.01 ), it fails to exhibit any impact on attitude in India, which is contrary to H10. Finally, the remaining constructs (informativeness, irritation and personalization) do not exhibit any significant differences between the two countries, which disproves $H 9, H 11$, and $H 12$. 
Table 7. Path coefficients for India and the UK

\begin{tabular}{lcccccc}
\hline & \multicolumn{3}{c}{ India } & \multicolumn{3}{c}{ UK } \\
\hline & Path coefficient & T Statistics & P Values & Path coefficient & T Statistics & P Values \\
\hline Attitude -> Behavioral intention & 0.91 & 51.68 & 0.00 & 0.89 & 41.20 & 0.00 \\
Credibility -> Attitude & 0.07 & 0.87 & 0.39 & 0.24 & 2.92 & 0.00 \\
Entertainment -> Attitude & 0.70 & 6.87 & 0.00 & 0.54 & 6.37 & 0.00 \\
Informativeness -> Attitude & 0.11 & 1.73 & 0.09 & 0.17 & 1.70 & 0.09 \\
Irritation -> Attitude & -0.05 & 1.13 & 0.26 & -0.09 & 1.42 & 0.16 \\
Personalization -> Attitude & 0.07 & 0.97 & 0.33 & -0.05 & 0.66 & 0.51 \\
\hline
\end{tabular}

\section{Discussion}

The results show significant correlations between beliefs, attitudes and behavioral intentions in the context of in-app advertisements aimed at smartphone users. Beliefs toward in-app advertising significantly predict attitude, which in turn predicts the intention to click on and pay further attention to in-app advertisements. This is in line with the findings of Raines (2013) who established that attitudes toward in-app advertising are significantly related to behavioral intentions. Similar to the results reported by Choi et al. (2008) and Raines (2013), our findings suggest that entertainment is the single most significant factor affecting attitudes in both countries. Thus, it seems that entertaining advertisements enjoy universal appeal. The effect of perceived entertainment value on attitudes toward in-app advertising was also found to be greater for Indian smartphone users, which is consistent with this study's initial hypothesis. Contrary to our expectations, perceived informativeness did not have any impact on the attitudes of smartphone users from either country toward in-app advertising. Thus, even smartphone users in the UK, when exposed to in-app advertising, appear to value entertainment more highly than information. One plausible explanation for this finding is that in-app advertising holds limited opportunities for informational cues compared to advertising on other 


\section{BEHAVIORAL INTENTIONS TOWARD MOBILE ADVERTISEMENTS}

platforms (see also Choi et al., 2008). This study's results contradict the findings of research conducted by Zabadi et al., (2012) and Tsang et al., (2004) in which informativeness was shown to have a significant impact on attitude.

Credibility has long been thought to have a significant effect on attitudes toward advertisements, with some researchers going so far as to consider it the principal factor (Chowdhury et al., 2006). However, the results of this study corroborate this hypothesis only as it relates to participants from the UK, and not in relation to Indian smartphone users. This means that, when participants find in-app advertisements to be trustworthy and credible, they have marginally more positive attitudes toward them. The results also show that cultural differences exist between UK and Indian smartphone users in terms of credibility. While credibility did not have a significant impact on the attitudes of Indian participants, it was found to have a significant effect on the attitudes of respondents from the UK. Participants also held the general view that advertisements were irritating, annoying and disturbing. As expected, irritation had a negative impact on attitudes when both groups were examined in combination, which is consistent with previous studies. However, there was no significant impact when the countries were examined separately, which suggests that no cultural difference exists in this regard. Finally, although personalization is considered to be an important feature of mobile advertisements as it incorporates demographic and behavioral information, personalization did not have a significant effect on attitude. One conceivable explanation for this result could be that advertisers are not implementing personalization in their advertising campaigns to the fullest extent possible. Participants might therefore be unfamiliar with comprehensively personalized advertisements.

The main purpose of this study was to provide knowledge for researchers, as well as for practitioners seeking to implement both local and international mobile advertising campaigns using in-app advertisements. The study was intended to supply the need for up-to- 


\section{BEHAVIORAL INTENTIONS TOWARD MOBILE ADVERTISEMENTS}

date research on the fast-developing field of in-app advertisements, and mobile marketing in general. More specifically, its findings add to the existing body of advertising research as well as the literature on cross-cultural advertising by constructing a conceptual model that incorporates the essential components of a number of theoretical foundations such as the TRA, UGT and Hofstede's cultural framework.

\subsection{Limitations and further research}

One of the limitations of this study is the data sampling method it utilized. As the respondent pool was not selected by means of probability sampling, it is not possible to generalize the study's findings to the entire population of the two countries. Despite this limitation, the acquisition of data by means of crowdsourcing services can provide valuable information in relation to in-app mobile advertisements, as the young people who form the largest demographic utilizing crowdsourcing services are also more likely than other population segments to own smartphones. In addition, compared to the more typical methods of gathering data from university students or via social media sites, crowdsourced samples have been shown to be significantly more socio-economically and ethnically diverse (e.g., Buhrmester, Kwang \& Gosling, 2011). Another limitation is that the study focused on in-app mobile advertisements as a whole, despite the existence of a variety of in-app advertisements, apps and mobile phones. Further research could examine whether attitudes toward in-app advertisements and users' willingness to click on, pay attention to and read in-app mobile advertisements are contingent on the type of app being used, or the type of advertisement encountered. The present study focused primarily on general perceptions in relation to in-app advertising, which is similar to the approach taken by Raines (2013). However, as Logan's (2017) more recent study indicates, smartphone users might be more favorably disposed toward advertising in assistance and informational apps compared to advertising in music and video apps. We also suggest that further studies examine cultural differences in this regard. 


\section{BEHAVIORAL INTENTIONS TOWARD MOBILE ADVERTISEMENTS}

\section{References}

Apple.com (2017). Developer earnings from the App Store top $\$ 70$ billion. Retrieved from www.apple.com/newsroom/2017/06/developer-earnings-from-the-app-store-top-70billion/

Bauer, H. H., Reichardt, T., Barnes, S. J., \& Neumann, M. M. (2005). Driving consumer acceptance of mobile marketing: A theoretical framework and empirical study. Journal of Electronic Commerce Research, 6(3), 181-191.

Billore, A., \& Sadh, A. (2015). Mobile advertising: A review of the literature. The Marketing Review, 15, 161-183. doi: 10.1362/146934715X14373846573586

Brackett, L. K., \& Carr, B. N. (2001). Cyberspace Advertising vs. Other Media: Consumer vs. Mature Student Attitudes. Journal Of Advertising Research, 41, 23-32. doi: 10.2501/JAR-41-5-23-32

Bhave, K., Jain, V., \& Roy, S. (2013). Understanding the orientation of Gen Y toward mobile applications and in-app advertising in India. International Journal of Mobile Marketing, $8(1), 62-71$.

Buhrmester, M., Kwang, T., \& Gosling, S. D. (2011). Amazon's Mechanical Turk a new source of inexpensive yet high-quality data? Perspectives on Psychological Science, 6, 3-5. doi: $10.1177 / 1745691610393980$

Cheng, J. M. S., Blankson, C., Wang, E. S. T., \& Chen, L. S. L. (2009). Consumer attitudes and interactive digital advertising. International Journal of Advertising, 28, 501-525. doi: $10.2501 / \mathrm{S} 0265048709200710$ 


\section{BEHAVIORAL INTENTIONS TOWARD MOBILE ADVERTISEMENTS}

Chin, W. W. (2010). How to write up and report PLS analyses. In V. E. Vinzi, W. W. Chin, J. Henseler \& H. Wang (Eds.), Handbook of partial least squares (pp. 655-690). Berlin: Springer.

Choi, Y. K., Hwang, J. S., \& McMillan, S. J. (2008). Gearing up for mobile advertising: A cross-cultural examination of key factors that drive mobile messages home to consumers. Psychology \& Marketing, 25, 756-768. doi: 10.1002/mar.20237

Chowdhury, H. K., Parvin, N., Weitenberner, C., \& Becker, M. (2006). Consumer attitude toward mobile advertising in an emerging market: An empirical study. International Journal of Mobile Marketing, 1(2), 33-41.

Dawar, N., \& Parker, P. (1994). Marketing universals: Consumers' use of brand name, price, physical appearance, and retailer reputation as signals of product quality. Journal of Marketing, 58, 81-95. doi: 10.2307/1252271

De Mooij, M. (2004). Translating advertising: painting the tip of an iceberg. The Translator, 10, 179-198. doi: http://dx.doi.org/10.1080/13556509.2004.10799176

De Mooij, M. \& Hofstede, G. (2010). The Hofstede model: Applications to global branding and advertising strategy and research. International Journal of Advertising, 29, 85-110. doi: $10.2501 / \mathrm{S} 026504870920104 \mathrm{X}$

Ducoffe, R. H. (1995). How consumers assess the value of advertising. Journal of Current Issues and Research in Advertising, 17, 1-18. doi: 10.1080/10641734.1995.10505022

Ducoffe, R. H. (1996). Advertising value and advertising on the web. Journal of advertising Research, 36(5), 21-21.

Erdem, T., Swait, J., \& Valenzuela, A. (2006). Brands as signals: A cross-country validation study. Journal of Marketing, 70, 34-49. doi: 10.1509/jmkg.2006.70.1.34 


\section{BEHAVIORAL INTENTIONS TOWARD MOBILE ADVERTISEMENTS}

eMarketer (2017). eMarketer unveils new estimates for mobile app usage. Retrieved from www.emarketer.com/Article/eMarketer-Unveils-New-Estimates-Mobile-AppUsage/1015611

Fishbein, M., \& Ajzen, I. (1975). Belief, Attitude, Intention, and Behavior: An Introduction to Theory and Research.Reading, MA: Addison-Wesley.

Fung, R., \& Lee, M. (1999). EC-trust (trust in electronic commerce): exploring the antecedent factors. AMCIS 1999 Proceedings, 179.

Gao, S., \& Zang, Z. (2014). An empirical examination of users' adoption of mobile advertising in China. Information Development. 32, 203-215. doi: 10.1177/0266666914550113

Hall, E. T. (1976). Beyond culture. New York: Anchor Books/Doubleday

Haghirian, P., Madlberger, M. \& Tanuskova, A. (2005) Increasing advertising value of mobile marketing: an empirical study of antecedents, Paper presented in the Proceedings of the $38^{\text {th }}$ Hawaii International Conference on System Sciences, Hawaii, January.

Haron, H., Mun, K. N. K., \& Ahmad, N. (2015). Consumer Attitude Towards Mobile Advertising. Advanced Science Letters, 21, 1452-1454. doi: https://doi.org/10.1166/asl.2015.6068

Hofstede, G. (1980). Culture and organizations. International Studies of Management \& Organization, 10, 15-41. doi: http://www.jstor.org/stable/40396875 .

Hofstede, G. (1984). Culture's Consequences: International Differences in Work-Related Values. Newbury Park, CA: Sage Publications.

Hofstede, G. (2001). Culture's consequences: Comparing values, behaviors, institutions, and organizations across nations. Thousand Oaks, CA: Sage 


\section{BEHAVIORAL INTENTIONS TOWARD MOBILE ADVERTISEMENTS}

Hong, J. W., Muderrisoglu, A., \& Zinkhan, G. M. (1987). Cultural differences and advertising expression: A comparative content analysis of Japanese and US magazine advertising. Journal of Advertising, 16, 55-68. doi: 10.1080/00913367.1987.10673061

House, R. J., Hanges, P. J., Javidan, M., Dorfman, P. W. \& Gupta, V. (Eds.). (2004). Culture, leadership, and organizations: The GLOBE study of 62 societies. Thousand Oaks, CA: Sage Publications.

Izquierdo-Yusta, A., Olarte-Pascual, C., \& Reinares-Lara, E. (2015). Attitudes toward mobile advertising among users versus non-users of the mobile Internet. Telematics and Informatics, 32, 355-366. doi: http://dx.doi.org/10.1016/j.tele.2014.10.001

Kaasinen, E. (2003). User Needs for Location-Aware Mobile Services. Personal and Ubiquitous Computing, 7, 70-79. doi: 10.1007/s00779-002-0214-7

Khalaf, S. (2016). Media, Productivity \& Emojis Give Mobile Another Stunning Growth Year Retrieved from http://flurrymobile.tumblr.com/post/136677391508/stateofmobile2015

Katz, E., Haas, H., \& Gurevitch, M. (1973). On the use of the mass media for important things. American sociological review, 38(2), 164-181. Retrieved from Retrieved from http://repository.upenn.edu/asc_papers/267

Khang, H., Han, S., Shin, S., Jung, A. R., \& Kim, M. J. (2015). A retrospective on the state of international advertising research in advertising, communication, and marketing journals: 1963-2014. International Journal of Advertising, 35. 1-29. doi: $10.1080 / 02650487.2015 .1066477$

Kim, Y. J., \& Han, J. (2014). Why smartphone advertising attracts customers: A model of Web advertising, flow, and personalization. Computers in Human Behavior, 33, 256-269. doi: http://dx.doi.org/10.1016/j.chb.2014.01.015 


\section{BEHAVIORAL INTENTIONS TOWARD MOBILE ADVERTISEMENTS}

Lee, C., \& Green, R. T. (1991). Cross-cultural examination of the Fishbein behavioral intentions model. Journal of International Business Studies, 22, 289-305. doi: 10.1057/palgrave.jibs. 8490304

Liu, C., Sinkovics, R. R., Pezderka, N., \& Haghirian, P. (2012). Determinants of consumer perceptions toward mobile advertising - a comparison between Japan and Austria. Journal of Interactive Marketing, 26, 21-32. doi: 10.1016/j.intmar.2011.07.002

Logan, K. (2017). Attitudes towards in-app advertising: a uses and gratifications perspective. International Journal of Mobile Communications, 15, 26-48. doi: 10.1504/IJMC.2016.10000002

MacKenzie, S. B., \& Lutz, R. J. (1989). An empirical examination of the structural antecedents of attitude toward the ad in an advertising pretesting context. The Journal of Marketing, 53, 48-65. doi: http://www.jstor.org/stable/1251413

McQuail, D. (1983). Mass Communication Theory: An Introduction. London: Sage Publication.

Moon, J., Chadee, D., \& Tikoo, S. (2008). Culture, product type, and price influences on consumer purchase intention to buy personalized products online. Journal of Business Research, 61, 31-39. doi: 10.1016/j.jbusres.2006.05.012

Moore, J. J., \& Rodgers, S. L. (2005, January). An examination of advertising credibility and skepticism in five different media using the persuasion knowledge model. Proceedings of the American Academy of Advertising, USA 10-18. Retrieved from https://search.proquest.com/docview/192395178?accountid=28419.

Murphy, D. (2017). 2.4bn smartphone users in 2017, says eMarketer. Mobile Marketing Magazine. Retrieved from http://mobilemarketingmagazine.com/24bn-smartphoneusers-in-2017-says-emarketer. 


\section{BEHAVIORAL INTENTIONS TOWARD MOBILE ADVERTISEMENTS}

Nielsen (2015). Recommendations from friends remain most credible form of advertising among consumers; Branded websites are the second-highest-rated form. Retrieved http://www.nielsen.com/eu/en/press-room/2015/recommendations-from-friends-remainmost-credible-form-of-advertising.html

Okazaki, S., \& Mueller, B. (2007). Cross-cultural advertising research: Where we have been and where we need to go. International Marketing Review, 24, 499-518. doi: $10.1108 / 02651330710827960$

Peng, B., \& Spencer, I. (2006). Mobile marketing - The Chinese perspective. International Journal of Mobile $\quad$ Marketing, $1, \quad 50-59 . \quad$ doi: http://dx.doi.org/10.1108/07363761011086326

Raines, C. (2013). In-app mobile advertising: investigating consumer attitudes towards pullbased mobile advertising amongst young adults in the UK. Journal of Promotional Communications, 1(1), 125-148.

Saadeghvaziri, F., \& Hosseini, H. K. (2011). Mobile advertising: An investigation of factors creating positive attitude in Iranian customers. African journal of business management, 5, 394-404. doi: 10.5897/AJBM10.431

Schwartz, S. H. (1994). Beyond individualism/collectivism: New cultural dimensions of values. In U. Kim, H. C. Triandis, C. Kagitçibasi, S. C. Choi \& G. Yoon (Eds.), Individualism and Collectivism: Theory, Method and Applications (pp. 85-119). Thousand Oaks, CA: Sage Publications.

Schwartz, S. H., \& Bilsky, W. Toward a universal psychological structure of human values. Journal of Personality and Social Psychology, 53, 550-562. doi: http://dx.doi.org/10.1037/0022-3514.53.3.550 


\section{BEHAVIORAL INTENTIONS TOWARD MOBILE ADVERTISEMENTS}

Siau, K., \& Shen, Z. (2003). Building Customer Trust in Mobile Commerce. Communications of the ACM, 46, 91-94. doi: 10.1145/641205.641211

Singh, N., Zhao, H., \& Hu, X. (2005). Analyzing the cultural content of web sites: A crossnational comparision of China, India, Japan, and US. International Marketing Review, 22, 129-146. doi: 10.1108/02651330510593241

Statista (2017a). Number of apps available in leading app stores as of March 2017. Retreived from www.statista.com/statistics/276623/number-of-apps-available-in-leading-appstores/

Statista (2007b). Cumulative number of apps downloaded from the Apple App Store from July 2008 to June 2017. Retreived from www.statista.com/statistics/263794/number-ofdownloads-from-the-apple-app-store/

Statista (2017c). Worldwide in-app advertising and app store revenues of mobile apps and games in 2015 and 2020. Retreived from www.statista.com/statistics/293636/app-storecomposition-business-models/

Statista (2017d). Most-used mobile app monetization models according to mobile developers worldwide as of June 2015. Retreived from www.statista.com/statistics/297024/mostpopular-mobile-app-monetization-models/

Sundar, S. S., \& Limperos, A. M. (2013). Uses and grats 2.0. New gratifications for new media. Journal of Broadcasting and Electronic Media, 57, 504-525. doi: http://dx.doi.org/10.1080/08838151.2013.845827

Taylor, C. R., Miracle, G. E., \& Wilson, R. D. (1997). The impact of information level on the effectiveness of US and Korean television commercials. Journal of Advertising, 26, 118. doi: http://www.jstor.org/stable/4189023 


\section{BEHAVIORAL INTENTIONS TOWARD MOBILE ADVERTISEMENTS}

Tellis, G. J., Stremersch, S., \& Yin, E. (2003). The international takeoff of new products: The role of economics, culture and country innovativeness. Marketing Science, 22, 188-208. doi: http://www.jstor.org/stable/4129714

Terlutter, R., Diehl, S., \& Mueller, B. (2006). The GLOBE study — applicability of a new typology of cultural dimensions for cross-cultural marketing and advertising research. In Diehl, S., \& Terlutter, R. (Eds). International Advertising and Communication: Current Insights and Empirical Findings (pp. 419-438). DUV.

Tsang, M. M., Ho, S. C., \& Liang, T. P. (2004). Consumer attitudes toward mobile advertising: An empirical study. International Journal of Electronic Commerce, 8(3), 65-78.

Turban, E., King, D., Lee, J. K., Liang, T. P., \& Turban, D. C. (2015). Electronic commerce: A managerial and social networks perspective. Springer International Publishing.

Van Everdingen, Y. M., \& Waarts, E. (2003). The effect of national culture on the adoption of innovations. Marketing Letters, 14, 217-232. doi: 10.1023/A:1027452919403

Wang, Y. \& Sun, S. (2010). Examining the role of beliefs and attitudes in online advertising: a comparison between the USA and Romania. International Marketing Review, 27, 87-107. doi: $10.1108 / 02651331011020410$

Watson, C., McCarthy, J., \& Rowley, J. (2013). Consumer attitudes towards mobile marketing in the smart phone era. International Journal of Information Management, 33, 840-849. doi: https://doi.org/10.1016/j.ijinfomgt.2013.06.004

Xu, D. J. (2006). The influence of personalization in affecting consumer attitude toward mobile advertising in China. The Journal of Computer Information Systems, 47(2), 9-21.

Yang, B., Kim, Y., \& Yoo, C. (2013). The integrated mobile advertising model: The effects of technology-and emotion-based evaluations. Journal of Business Research, 66, 13451352. doi: http://dx.doi.org/10.1016/j.jbusres.2012.02.035 


\section{BEHAVIORAL INTENTIONS TOWARD MOBILE ADVERTISEMENTS}

Zabadi, A. M. A., Shura, M., \& Elsayed, E. A. (2012). Consumer attitudes toward SMS advertising among Jordanian users. International Journal of Marketing Studies, 4(1), 77. doi: 10.5539/ijms.v4n1p77 